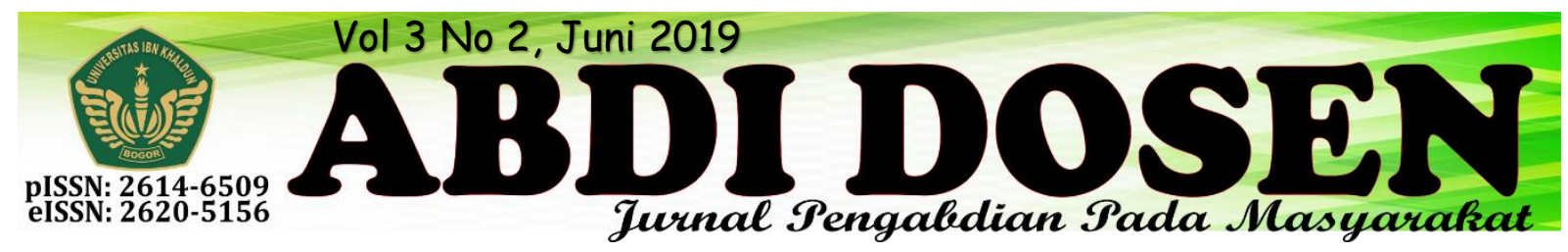

\title{
PEMBERDAYAAN MASYARAKAT KAMPUNG TAMANSARI DESA KARYASARI
}

\author{
Widhi Ario Bimo ${ }^{1}$, Bima Fitrah ${ }^{2}$ \\ widhi@uika-bogor.ac.id ${ }^{1}$ \\ bimafitrah8@gmail.com $^{2}$ \\ Fakultas Ekonomi Universitas Ibn Khaldun ${ }^{1}$, Mahasiswa KKN Kelompok 56 Tahun $2018^{2}$
}

\begin{abstract}
ABSTRAK
Pemberdayaan masyarakat adalah proses pembangunan dimana masyarakat berinisiatif untuk memulai proses kegiatan sosial untuk memperbaiki situasi dan kondisi diri sendiri. Kesehatan merupakan salah satu aspek kehidupan yang penting, namun masih banyak masyarakat yang mengabaikannya. Masyarakat cenderung sadar akan pentingnya kesehatan setelah merasakan sakit. Oleh karena itulah, masyarakat lebih sering melakukan upaya kuratif daripada upaya preventif dan promotif. Kondisi tersebut juga dialami oleh masyarakat Desa Karyasari. Selain kurangnya kesadaran masyarakat mengenai kesehatan, pemahaman mengenai hukum juga tergolong rendah. Banyak masyarakat yang belum memahami bagaimana seharusnya hubungan Perangkat Desa dengan masyarakat. Mahasiswa sebagai kaum intelektual memiliki peran penting dalam meningkatkan kesadaran masyarakat mengenai kesehatan dan pemahaman hukum. Selain itu, Desa Karyasari memiliki potensi hasil umbi-umbian seperti ubi, singkong dan talas yang dapat dijadikan peluang ekonomi. Beberapa masyarakat sudah mulai mengolah hasil umbi-umbian tersebut menjadi olahan pangan khas Kampung Tamansari seperti keripik ubi pelangi. Namun hambatan yang dirasakan oleh para pengusaha keripik dalam mengemban usaha tersebut adalah belum adanya merek atau label penjualan, packaging, dan pemasaran produk. Untuk mengatasi permasalahan tersebut, mahasiswa berupaya melakukan pengembangan usaha kecil menengah yang diharapkan mampu mengembangkan usaha masyarakat. Upaya-upaya yang dilakukan oleh mahasiswa melalui pemberdayaan masyarakat dalam berbagai bidang diharapkan mampu meningkatkan Indeks Pembangunan Manusia (IPM).
\end{abstract}

Kata Kunci: Pemberdayaan masyarakat, Kesehatan, Pemahaman hukum, Usaha kecil menengah, Indeks pembangunan manusia

\section{PENDAHULUAN}

\section{Latar Belakang}

Desa Karyasari merupakan desa yang berada di Kecamatan Leuwiliang Kabupaten Bogor. Letak Desa Karyasari sekitar $\pm 5 \mathrm{KM}$ dari kantor Kecamatan Leuwiliang. Mayoritas penduduk Desa Karyasari bekerja sebagai buruh harian lepas dan petani. Masyarakat memanfaatkan lahan kebun yang ada untuk ditanami umbi-umbian seperti ubi, singkong, dan talas. Hasil bumi berupa umbi-umbian ini biasanya dijual untuk membantu pemasukan kebutuhan hidup sehari-hari. Selain itu, ada pula masyarakat 
yang mengolahnya menjadi produk keripik yang dipasarkan melalui warung-warung kecil di Desa Karyasari.

Kesadaran masyarakat Desa Karyasari terhadap pendidikan masih tergolong rendah, karena sebagian besar hanya tamat $\mathrm{SD} /$ sederajat meskipun ada beberapa masyarakat yang melanjutkan pendidikan hingga jenjang perguruan tinggi. Rendahnya kesadaran masyarakat Desa Karyasari terhadap pendidikan dapat disebabkan karena jarak tempuh ke sekolah khususnya SMP/sederajat dan SMA/sederajat yang cukup jauh. Selain itu, kurangnya tenaga pendidik di Desa Karyasari juga menjadi salah satu hambatan yang harus diperhatikan. Banyak guru yang harus merangkap ke mata pelajaran lain yang sebenarnya bukan menjadi keahlian guru tersebut.

Dalam bidang kesehatan, masyarakat Desa Karyasari banyak yang menderita hipertensi atau tekanan darah tinggi. Selain itu, kesadaran masyarakat untuk berperilaku hidup bersih dan sehat sejak dini masih tergolong rendah. Sedangkan dalam bidang teknik, masih banyak masyarakat yang belum mampu mengoperasikan komputer.

Berdasarkan prioritas masalah tersebut, kelompok KKN 56 berusaha untuk mencari alternatif pemecahan masalah melalui program-program kerja yang dijelaskan dalam Realisasi Program.

\section{Keadaan Geografis}

Desa Karyasari merupakan salah satu desa di wilayah Kecamatan Leuwiliang Kabupaten Bogor Provinsi Jawa Barat dengan luas wilayah $658,20 \mathrm{Ha}$ dan titik koordinat 106.6347 BT / -6.614502 LS. Desa Karyasari terdiri dari 10 Rukun Warga (RW) dan 37 Rukun Tetangga (RT) dengan batas wilayah sebagai berikut:

\begin{tabular}{|c|l|l|}
\hline No. & \multicolumn{1}{|c|}{ Arah } & \multicolumn{1}{|c|}{ Wilayah } \\
\hline 1. & Utara & Desa Karacak \\
\hline 2. & Selatan & Desa Puraseda \\
\hline 3. & Barat & Desa Pabangbon \\
\hline 4. & Timur & $\begin{array}{l}\text { Kecamatan } \\
\text { Pamijahan }\end{array}$ \\
\hline
\end{tabular}

\section{Keadaan Demografi}

Jumlah penduduk Desa Karyasari tercatat sebanyak 8.411 jiwa.

\section{Pekerjaan}

\begin{tabular}{|c|c|c|c|}
\hline Jenis Pekerjaan & $\begin{array}{l}\text { Laki-Lak } \\
\text { (orang) }\end{array}$ & $\begin{array}{l}\text { i Perempuan } \\
\text { (orang) }\end{array}$ & $\begin{array}{l}\text { Jumlah } \\
\text { (Orang) }\end{array}$ \\
\hline Petani & 108 & 0 & 108 \\
\hline Buruh Tani & 51 & 0 & 51 \\
\hline $\begin{array}{l}\text { Pegawai Negeri } \\
\text { Sipil }\end{array}$ & 21 & 12 & 33 \\
\hline Pengrajin & 40 & 40 & 80 \\
\hline Peternak & 6 & 0 & 6 \\
\hline Montir & 15 & 0 & 15 \\
\hline Perawat swasta & 0 & 1 & 1 \\
\hline Bidan swasta & 0 & 1 & 1 \\
\hline $\begin{array}{l}\text { Ahli Pengobatan } \\
\text { Alternatif }\end{array}$ & 5 & 0 & 5 \\
\hline TNI & 2 & 0 & 2 \\
\hline $\begin{array}{l}\text { Pengusaha kecil, } \\
\text { menengah dan } \\
\text { besar }\end{array}$ & 200 & 0 & 200 \\
\hline Guru swasta & 30 & 27 & 57 \\
\hline $\begin{array}{l}\text { Pedagang } \\
\text { Keliling }\end{array}$ & 129 & 4 & 133 \\
\hline Penambang & 1 & 1 & 2 \\
\hline $\begin{array}{l}\text { Pembantu rumah } \\
\text { tangga }\end{array}$ & 1 & 9 & 10 \\
\hline $\begin{array}{l}\text { Dukun } \\
\text { Tradisional }\end{array}$ & 0 & 4 & 4 \\
\hline $\begin{array}{l}\text { Karyawan } \\
\text { Perusahaan } \\
\text { Swasta }\end{array}$ & 330 & 64 & 394 \\
\hline $\begin{array}{l}\text { Karyawan } \\
\text { Perusahaan } \\
\text { Pemerintah }\end{array}$ & 4 & 0 & 4 \\
\hline
\end{tabular}




\begin{tabular}{|l|l|l|l|}
\hline Wiraswasta & 729 & 50 & 779 \\
\hline Belum Bekerja & 914 & 785 & 1.699 \\
\hline Pelajar & 1.007 & 905 & 1.912 \\
\hline $\begin{array}{l}\text { Ibu Rumah } \\
\text { Tangga }\end{array}$ & 7 & 1.847 & 1.854 \\
\hline $\begin{array}{l}\text { Purnawirawan/P } \\
\text { ensiunan }\end{array}$ & 24 & 6 & 30 \\
\hline $\begin{array}{l}\text { Perangkat Desa } \\
\text { Buruh Harian }\end{array}$ & 8 & 0 & 8 \\
\hline $\begin{array}{l}\text { Lepas } \\
\text { Pemilik usaha } \\
\text { jasa transportasi } \\
\text { dan perhubungan }\end{array}$ & 5 & 32 & 841 \\
\hline Sopir & 49 & 0 & 5 \\
\hline Tukang Jahit & 1 & 0 & 1 \\
\hline $\begin{array}{l}\text { Karyawan } \\
\text { Honorer }\end{array}$ & 4 & 3 & 7 \\
\hline Pemuka Agama & 7 & 0 & 7 \\
\hline \begin{tabular}{l} 
Jumlah Total \\
\hline
\end{tabular} & 4.507 & 3.791 & 8.298 \\
\hline
\end{tabular}

\begin{tabular}{|c|c|c|c|}
\hline \multirow{2}{*}{\multicolumn{4}{|c|}{$\begin{array}{l}\text { (Orang) } \\
\text { Pendidikan }\end{array}$}} \\
\hline & & & \\
\hline $\begin{array}{l}\text { Tingkatan } \\
\text { Pendidikan }\end{array}$ & $\begin{array}{l}\text { Laki- } \\
\text { Laki } \\
\text { (orang) }\end{array}$ & $\begin{array}{l}\text { Perempuan } \\
\text { (orang) }\end{array}$ & $\begin{array}{l}\text { Jumlah } \\
\text { (Orang) }\end{array}$ \\
\hline $\begin{array}{l}\text { Tamat } \\
\text { SD/sederajat }\end{array}$ & 1.788 & 1.860 & 3.648 \\
\hline $\begin{array}{l}\text { Tamat } \\
\text { SMP/sederajat }\end{array}$ & 1.030 & 800 & 1.830 \\
\hline $\begin{array}{l}\text { Tamat } \\
\text { SMA/sederajat }\end{array}$ & 613 & 365 & 978 \\
\hline $\begin{array}{l}\text { Tamat D- } \\
\text { 2/sederajat }\end{array}$ & 15 & 13 & 28 \\
\hline $\begin{array}{l}\text { Tamat S- } \\
\text { 1/sederajat }\end{array}$ & 45 & 25 & 70 \\
\hline $\begin{array}{l}\text { Tamat S- } \\
\text { 2/sederajat }\end{array}$ & 1 & 0 & 1 \\
\hline $\begin{array}{l}\text { Jumlah Total } \\
\text { (Orang) }\end{array}$ & 3.492 & 3.063 & 6.555 \\
\hline
\end{tabular}

\section{METODE PENGABDIAN}

\section{Tahap Pelaksanaan}

Tahapan pelaksanaan untuk kegiatan ini sebagaimana terlihat pada bagan sebagai berikut:

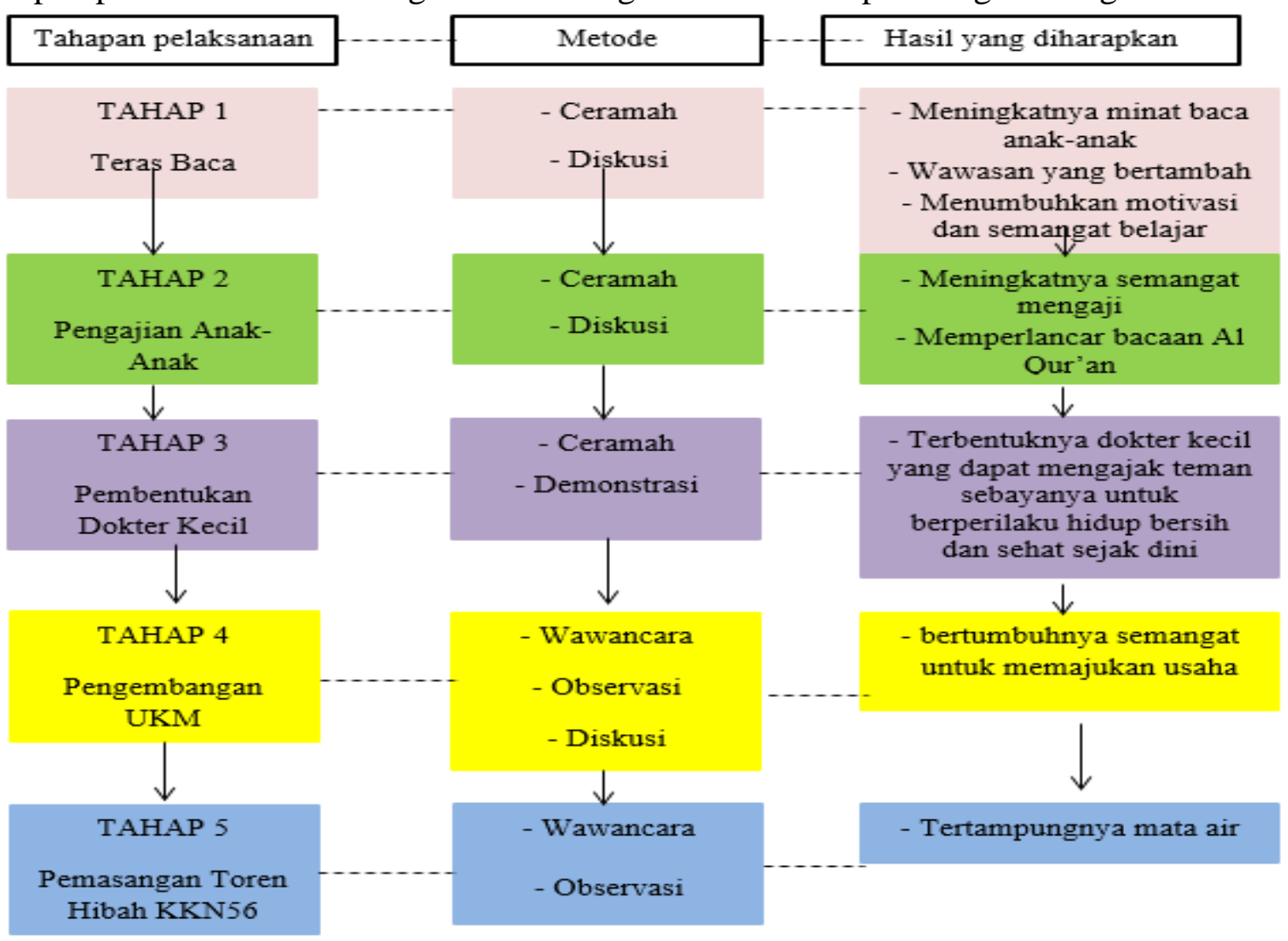




\section{Metode Pendekatan}

Pendekatan yang digunakan dalam kegiatan ini adalah:

a. Pendekatan religius, yaitu pendekatan yang menggunakan nilai-nilai agama sebagai basis kegiatan.

b. Pendekatan berdasarkan karakter masyarakat, yakni pembinaan yang dilakukan akan disesuaikan dengan karakter masyarakat.

\section{Partisipasi Masyarakat Dalam} Pelaksanaan Program

Partisipasi masyarakat yang dapat dilakukan dalam kegiatan ini adalah sebagai berikut:

a. Mempersiapkan anak-anak yang bersedia mengikuti bimbingan belajar dan pengajian anak-anak.

\section{REALISASI PROGRAM}

Pada pelaksanaan Kuliah Kerja Nyata (KKN) Tematik Terintegrasi 2018 selama 28 hari, kelompok 56 telah merealisasikan beberapa program sebagai berikut:

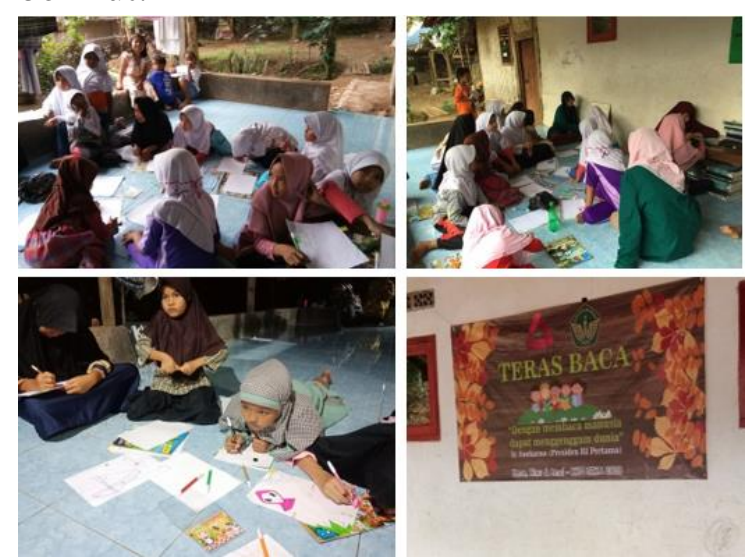

a. Teras Baca

Penyediaan sarana membaca seperti majalah, buku pelajaran dan buku yang memuat ilmu pengetahuan lainnya serta kertas bergambar yang bisa diwarnai dan berbagai media lain untuk menyalurkan krearivitas anak. Sasaran program teras baca ini adalah masyarakat seluruh usia. b. Menghadiri seminar hukum dan cek kesehatan gratis.

c. Bersama-sama memasang toren air.

\section{Langkah Evaluasi}

Gambaran evaluasi yang dilakukan terdiri dari:

a. Evaluasi proses, dilaksanakan selama proses/pelaksanaan kegiatan KKN berlangsung baik pada waktu perencanaan maupun pada waktu tahapan kegiatan. Evaluasi proses berkaitan dengan perencanaan, pelaksanaan dan monitoring kegiatan.

b. Evaluasi hasil, dilakukan setelah kegiatan dilaksanakan. Evaluasi hasil berkaitan dengan pencapaian progam.
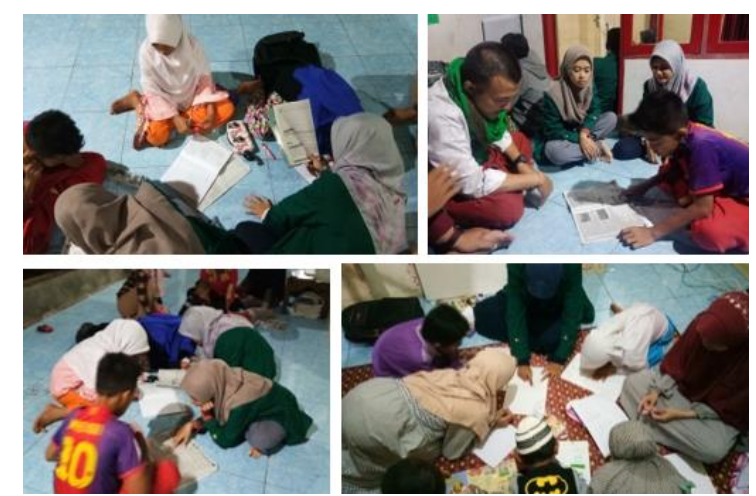

b. Bimbingan Belajar

Kegiatan membimbing anak dalam latihan mengerjakan soal-soal bertujuan untuk membantu anak yang kesulitan dalam belajar, untuk mengembangkan atau melatih kemampuan membaca, menulis dan berhitung, serta untuk menambah wawasan khususnya pada permasalahan pembelajaran yang sedang dihadapi anak. Sasaran dalam bimbingan belajar ini adalah murid SD dan SMP. 

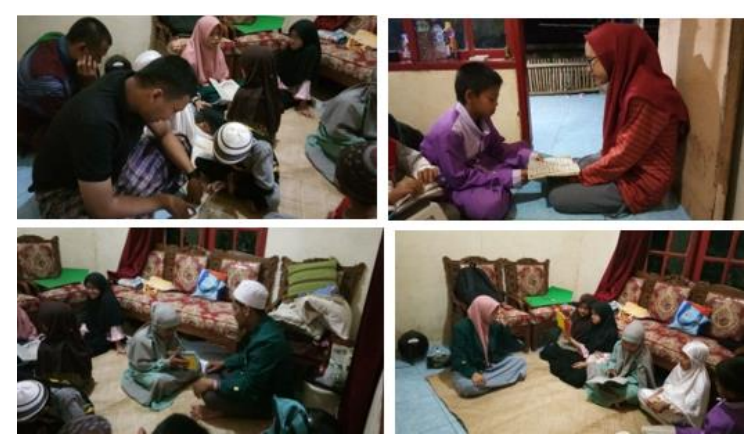

c. Pengajian Anak Anak

Pengajian dengan anak-anak yang dilaksanakan rutin selama 5 kali dalam seminggu. Pengajian ini diisi dengan kegiatan membaca iqro' atau al qur'an, pelatihan tahsin, pendidikan akhlak, serta dongeng kisah nabi dan rosul. Sasaran kegiatan pengajian ini adalah anak PAUD, SD dan SMP.
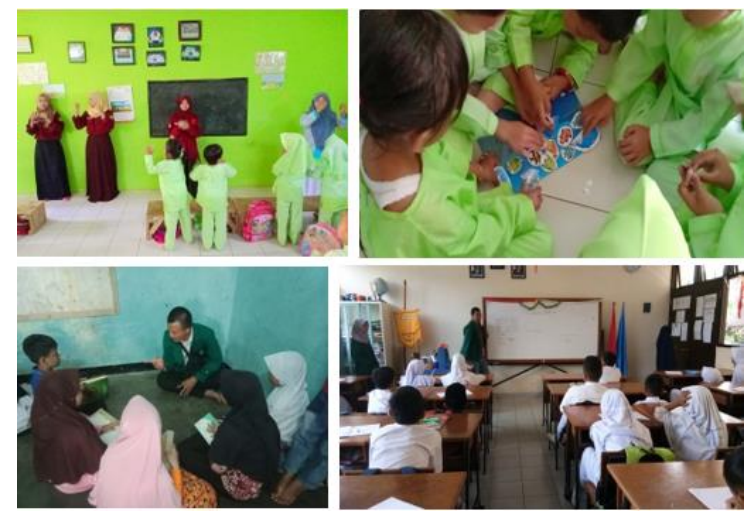

d. Mengajar

Kegiatan mengajar dilakukan pada 3 sasaran tempat yaitu PAUD, SD dan Diniyah.

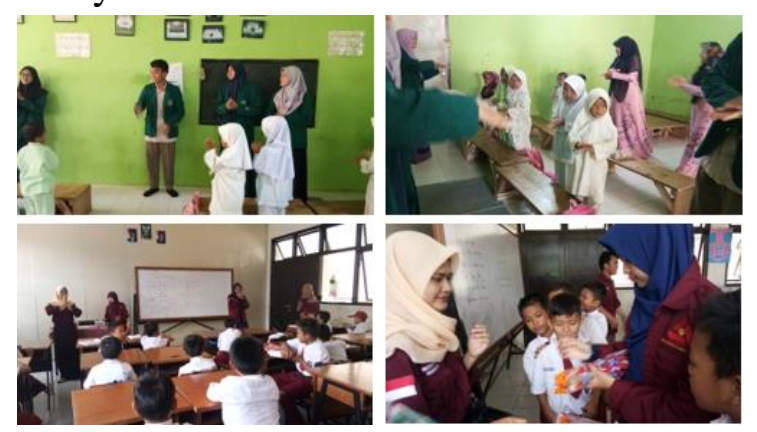

e. Penyuluhan Kesehatan

Kegiatan penyuluhan mengenai Perilaku Hidup Bersih dan Sehat (PHBS) seperti langkah-langkah cuci tangan dan sikat gigi yang baik dan benar. Sasaran dalam penyuluhan kesehatan adalah murid PAUD dan SD.
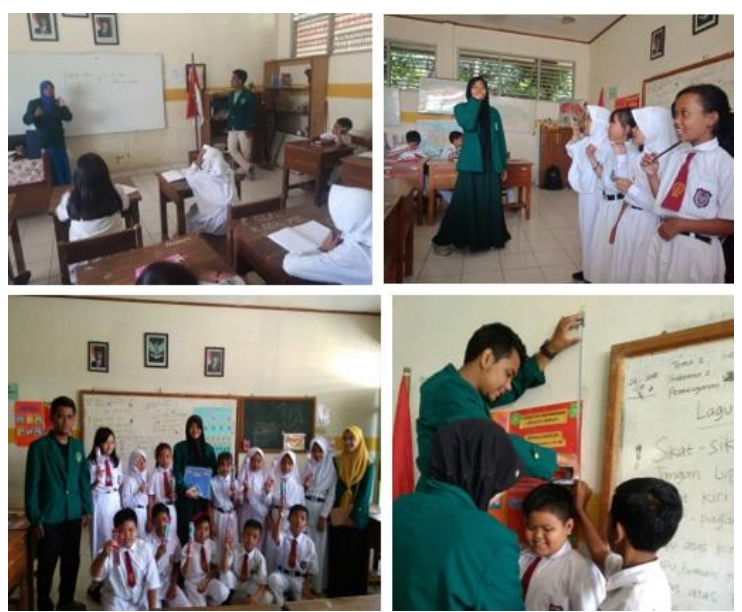

f. Pembentukan Dokter Kecil

Kegiatan pembentuan dokter kecil dilakukan di SDN Karyasari 02 dengan memberikan beberapa kali penyuluhan.

Diantaranya penyuluhan cuci tangan dan sikat gigi yang baik dan benar serta pelatihan mengukur berat badan dan tinggi badan.

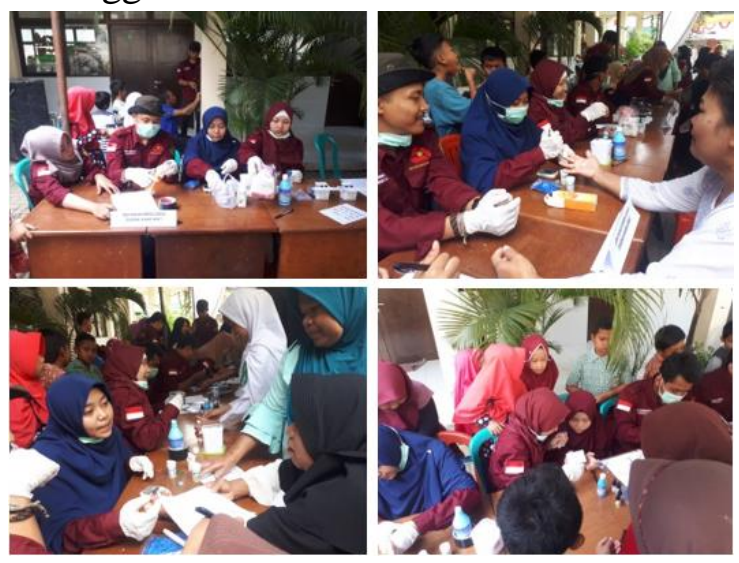

g. Cek Kesehatan Gratis

Penyediaan layanan cek kesehatan gratis untuk masyarakat Desa Karyasari baik anak-anak maupun dewasa. Cek kesehatan ini terdiri dari cek indeks massa tubuh, cek tekanan darah, cek golongan darah, cek asam urat, cek kolesterol dan cek gula darah. 

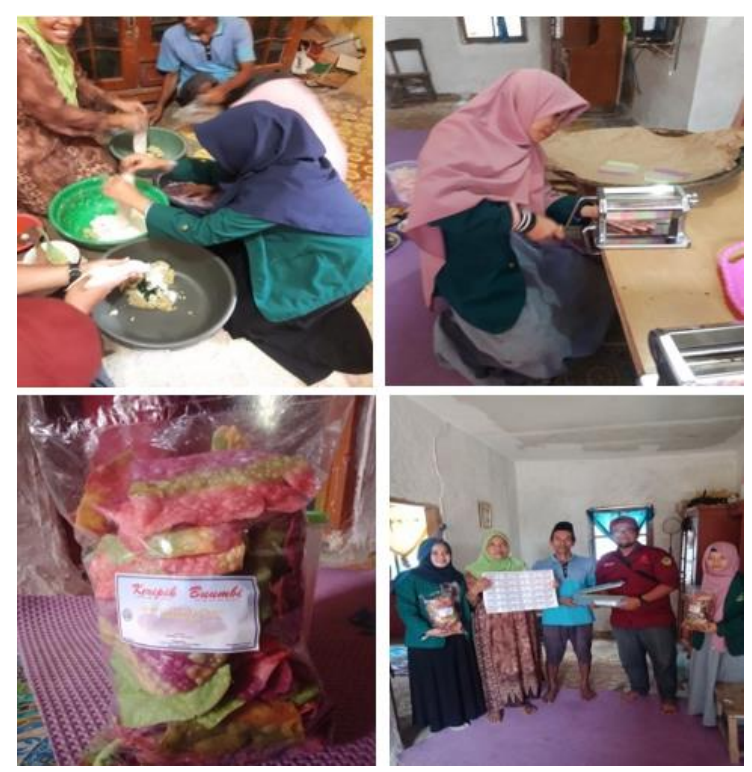

h. Pengembangan Usaha Kecil Menengah

Kegiatan pengembangan usaha keripik masyarakat dengan program sharing mengenai usaha mereka seperti pemasaran kemasan produksi dan kendala yang dialami. Maka mahasiswa memberikan masukan dan arahan kepada masyarakat yang memproduksi keripik guna mengembangkan usahanya. Seperti pemberian label dan merek dagang, packaging menggunakan sealer sebagai perekat, dan motivasi untuk memajukan usahanya. Hal ini dilakukan dengan cara door to door ke setiap produksi rumahan.
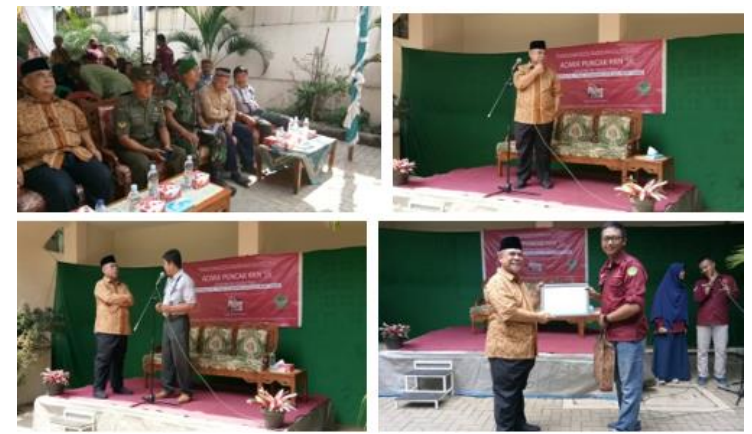

i. Seminar Hukum

Seminar mengenai hukum yang mengangkat tema Hubungan Perangkat Desa dengan Masyarakat, dengan mengundang bapak $\mathrm{H}$. $\mathrm{Tb}$ Soenmandjaja yang merupakan anggota DPR RI sebagai pemateri. Sasaran dalam seminar tersebut adalah masyarakat usia dewasa dan para tokoh masyarakat Desa Karyasari.
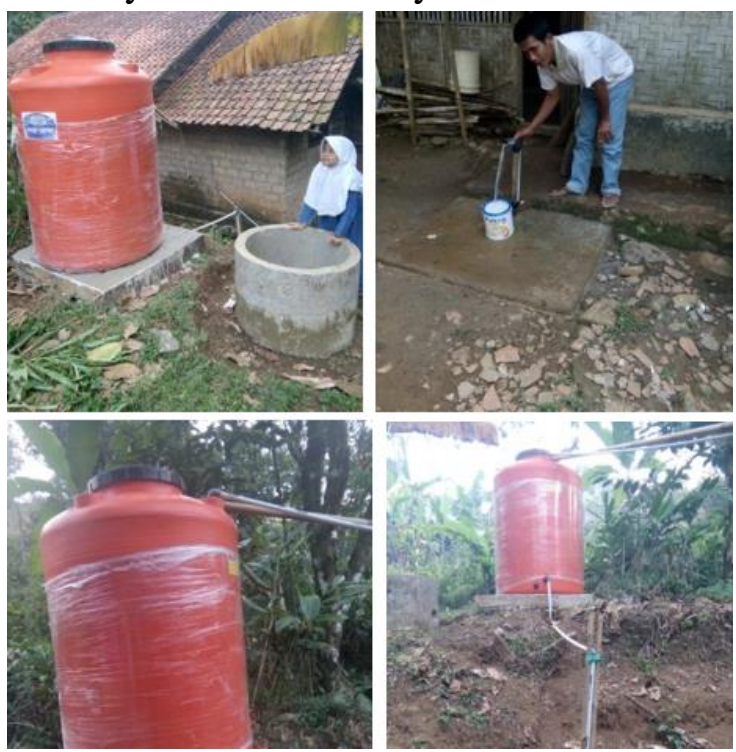

j. Pemasangan Toren Air

Program yang dilaksanakan untuk menanggulangi permasalahan sulitnya air. Toren tersebut dipasang di kampung Tamansari dekat dengan posko KKN kelompok 56.

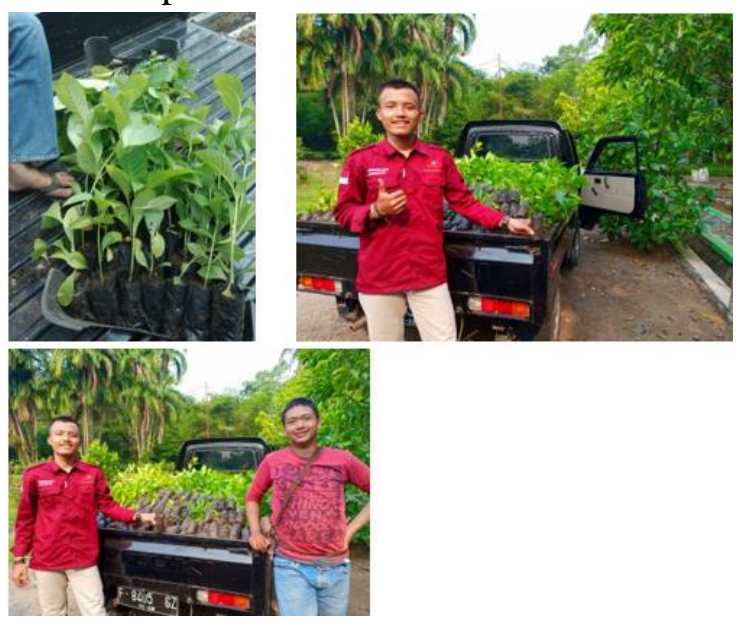

k. Pembagian Bibit Pohon

Desa Karyasari merupakan desa yang memiliki banyak lahan pekebunan, oleh karen itu kelompok KKN 56 membagikan \pm 800 bibit pohon yang terdiri dari bibit pohon jabon, salam, sirsak, durian, manga, dan lain-lain. Bibit-bibit pohon tersebut dibagikan kepada warga melalui ketua RT dan 
sebagian langsung ditanam di tanah wakaf.

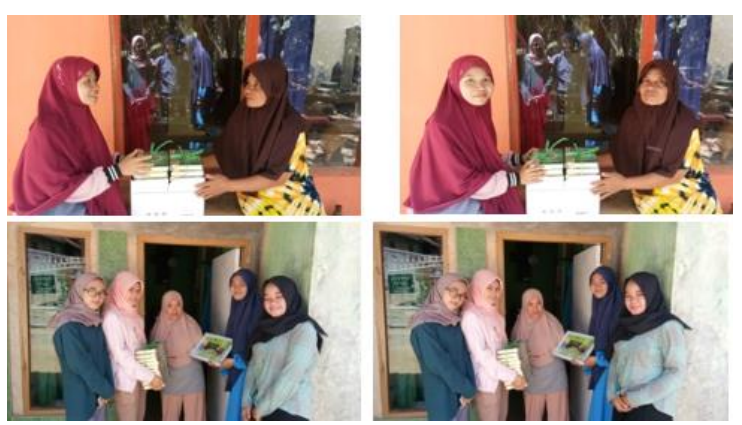

1. Pembagian Al Qur'an

Sebanyak 150 Al Qur'an yang diperoleh dari Yayasan Pendidikan Ibn Khaldun dibagikan kepada anak-anak, majelis ta'lim dan masjid yang ada di sekitar Desa Karyasari.

\section{KESIMPULAN}

\section{Dampak bagi masyarakat}

a. Bidang Pendidikan

Berbagai kegiatan dalam bidang pendidikan yang dilaksanakan di Desa Karyasari sangat dirasakan dampaknya bagi masyarakat. Dengan adanya Teras Baca, minat baca masyarakat Desa Karyasari khususnya anak-anak menjadi lebih meningkat. Selain itu, hobi anakanak dalam menggambar dan mewarnai dapat lebih mudah tersalurkan karena di Teras Baca juga disediakan kertas bergambar dan alat-alat untuk mewarnai seperti crayon, spidol, pensil. Kegiatan Bimbel atau bimbingan belajar juga sangat bermanfaat bagi anak-anak Desa Karyasari, karena dapat meningkatkan semangat belajar dan menambah wawasan. Program bidang pendidikan lainnya yaitu mengajar di PAUD, SD, dan Diniyah. Dengan keterbatasan tenaga pendidik di Desa Karyasari, program mengajar menjadi sangat bermanfaat tidak hanya bagi murid tetapi juga bagi guru maupun pihak sekolah.

\section{b. Bidang Kesehatan}

Dengan adanya program penyuluhan mengenai cuci tangan dan sikat gigi yang baik dan benar, anak-anak menjadi lebih menyadari pentingnya menjaga perilaku hidup bersih dan sehat sejak dini. Sedangkan program pembentukan dokter kecil di SDN Karyasari 2, selain bermanfaat bagi anak-anak yang terlibat, juga bermanfaat bagi guru dan sekolah dalam rangka mewujudkan Unit Kesehatan Sekolah (UKS). Selain itu, program cek kesehatan gratis adalah program yang paling banyak dirasakan manfaatnya secara langsung. Masyarakat lebih mengetahui kondisi kesehatannya sehingga memotivasi masyarakat agar lebih menjaga kesehatan dan melakukan tindakan pencegahan sejak dini.

c. Bidang Ekonomi

Dampak yang dirasakan oleh masyarakat dengan adanya program pengembangan Usaha Kecil Menengah (UKM) yaitu bertumbuhnya semangat untuk memajukan usaha keripiknya dengan memperbaiki kemasan agar lebih menarik guna menambah nilai jual 
keripik olahan masyarakat Desa Karyasari. Dan memperluas pemasaran keripik agar dikenal oleh masyarakat luas.

d. Bidang Agama

Dampak yang dirasakan dengan adanya program pengajian anak-anak adalah meningkatnya semangat anak-anak untuk mengaji dan bertumbuhnya motivasi anak-anak untuk senantiasa berakhlak baik.

e. Bidang Teknik

Dengan adanya program pemasangan toren air, masyarakat menjadi lebih mudah dalam mengakses air ketika musim kemarau.

f. Bidang Hukum

Dengan adanya seminar hukum, masyarakat menjadi lebih mengetahui bagaimana seharusnya hubungan antara perangkat desa dengan masyarakat. Serta menambah wawasan masyarakat mengenai perannya dalam kemajuan Desa.

g. Penghijauan Lingkungan

Dengan adanya pembagian ratusan bibit pohon, dampak yang dirasakan oleh masyarakat adalah lingkungan yang lebih asri dan hijau, tumbuhnya kepedulian masyarakat dalam merawat lingkungan sekitar dan keuntungan secara ekonomi dari hasil bibit pohon yang dapat dijual.

\section{Saran}

a. Bidang Pendidikan

Setelah melaksanakan program dan merasakan secara langsung hambatan dalam bidang pendidikan di Desa Karyasari, kami berharap agar Perangkat Desa segera memfasilitasi gedung untuk SMP kelas jauh. Agar tidak perlu lagi bergantian dengan murid SD menggunakan gedung SDN Karyasari 01. Hal tersebut guna memperlancar kegiatan belajar mengajar sehingga murid SMP bisa masuk sekolah di pagi hari.

b. Bidang Kesehatan

Demi keberlanjutan program yang telah dilaksanakan, kami berharap agar pihak sekolah SD Karyasari 2 terus memberdayakan dokter kecil yang telah dibentuk dan diberi pelatihan. Kami berharap dengan adanya pembentukan dokter kecil mampu menghidupkan kegiatan UKS yang ada di SD Karyasari 2.

c. Bidang Ekonomi

Kami merekomendasikan kepada perangkat desa agar lebih memperhatikan potensi ekonomi yang ada di Desa Karyasari khususnya hasil bumi berupa umbi-umbian yang dapat diolah menjadi keripik.

d. Bidang Agama

Setelah melaksanakan program dan merasakan secara langsung hambatan dalam bidang agama di Desa Karyasari, kami merekomendasikan agar sarana ibadah di Desa Karyasari khususnya masjid dapat dioptimalkan penggunaannya sehingga tidak terbengkalai. Seperti mengadakan kegiatan-kegiatan menarik yang berpusat di masjid dengan sasaran seluruh lapisan masyarakat.

e. Bidang Hukum

Setelah melaksanakan seminar hukum dengan tema Hubungan Perangkat Desa dengan Masyarakat, kami berharap agar materi yang telah disampaikan dalam seminar dapat diimplementasikan oleh masyarakat dan perangkat desa guna kemajuan Desa Karyasari. Selain itu, kami merekomendasikan kepada perangkat desa agar lebih sering berdiskusi langsung dengan masyarakat atau mengadakan rapat dengar pendapat 
secara rutin agar perangkat desa lebih memahami permasalahan yang terjadi dalam masyarakat.

\section{REFERENSI}

Rosyadi, A. Rahmat dan Prasetya, Eska Perdana. 2018. Petunjuk Pelaksanaan KKN Tematik Terintegrasi 2018 Universitas Ibn Khaldun Bogor. Bogor. UIKA Press.

http://kecamatanleuwiliang.bogorkab.go.id /index.php/multisite/detail_desa/262

Bimo, Widhi Aryo. Dkk. Maret 2018. Moralitas, Integritas dan Kreatifitas di Kampung Iwul.
Sulistyo. 2010. Pengembangan Usaha Kecil Dan Menengah Dengan Basis Ekonomi Kerakyatan Di Kabupaten Malang. Malang.

$\begin{array}{crr}\text { Jauhari, Jaidan. } & 2010 . & \text { Upaya } \\ \text { Pengembangan } & \text { Usaha } & \text { Kecil Dan } \\ \text { Menengah } & \text { (Ukm) } & \text { Dengan } \\ \text { Memanfaatkan } & \text { E-Commerce. } \\ \text { Palembang. } & & \end{array}$

